\title{
P. Arner \\ Resistin: yet another adipokine tells us that men are not mice
}

Published online: 29 September 2005

(C) Springer-Verlag 2005

Interest in adipose tissue research increased markedly after the discovery, now 15 years old, that adipocytes produce and release proteins with biological activity, including the hormones leptin and adiponectin and the cytokines TNF- $\alpha$ and IL-6. These so-called adipokines are of particular interest in the field of type 2 diabetes, because they may link obesity to impaired glucose metabolism and insulin resistance in muscle and liver, in addition to adipose tissue itself, through paracrine/autocrine effects [1]. Several adipokines, such as adiponectin, TNF- $\alpha$ and IL-6, have the potential to regulate glucose metabolism and insulin action directly in the target organs upon which insulin acts. Others, such as leptin, may have indirect effects. Most of our ideas about the role of adipokines are, however, derived from studies in mice, and subsequent investigations in man have often produced markedly different results. The first example of this is adipsin [2], a protein produced by adipocytes in mice and released into the circulation. Adipsin production is decreased in obese mice, and the protein was originally thought to protect against obesity and its associated complications of insulin resistance and type 2 diabetes. Subsequent human investigations failed to confirm this hypothesis [3], and the observation of slightly increased adipsin levels in obese individuals pointed, if anything, to the opposite conclusion. Interest in adipsin in the field of diabetes research promptly dissipated.

The next example is TNF- $\alpha$, which is produced in large amounts by fat cells of obese mice [4]. This cytokine is released into the circulation and, in obese animals, insulin resistance can be counteracted by neutralising TNF- $\alpha$ with antibodies. Human studies, in contrast, revealed that TNF- $\alpha$ is not released into the circulation [5], but is simply a local factor within our adipose tissue. Furthermore, intravenous treatment of obese, insulin-resistant humans with a TFN- $\alpha$

\footnotetext{
P. Arner $(\square)$

Department of Medicine, Karolinska Institute,

Huddinge University Hospital,

14186 Huddinge, Sweden

e-mail: peter.arner@medhs.ki.se

Tel.: +46-8-58582342

Fax: $+46-8-58582407$
}

antagonist failed to normalise insulin sensitivity [6]. The link between TNF- $\alpha$, obesity and insulin resistance in man is thus indirect, and can probably be explained by a local stimulatory effect of TNF- $\alpha$ on adipocyte lipolysis, and thereby the release of NEFAs into the circulation [1]. TNF- $\alpha$ production by adipose tissue is increased in obese humans, and may contribute to the elevated circulating NEFAs seen in obesity, which, in turn, has adverse consequences for diabetes. Adipose tissue contributes to circulating IL-6 in humans [5], and elevated levels of IL-6 are strongly linked to insulin resistance [1]. In contrast, IL-6 knockout mice develop insulin resistance and impaired glucose metabolism [7].

Resistin is the most recent example of an adipokine with contrasting roles in mouse and man. This protein was initially shown to be released in large amounts from mouse adipocytes; its release was increased in obese mice and accompanied by insulin resistance [8]. The adverse effects of obesity were neutralised by antibodies against resistin, and rosiglitazone reduced resistin levels. Adipocyte-derived resistin was therefore thought to link obesity to diabetes [8]. Most subsequent studies of resistin in mouse models, but not all, support the notion that resistin is an adipokine regulator of insulin action [9]. Once again, human studies show an entirely different picture. Human fat cells, unlike those of mice, do not produce resistin [10], although segments of human adipose tissue do release it [11]. Resistin is therefore not a true adipokine in man, but must be derived from as yet unidentified cells in the stromal compartment of human adipose tissue. Does resistin influence insulin sensitivity in man? Probably not, according to the study by Utzschneider et al. [12] published in this issue of Diabetologia. These authors measured plasma resistin in 177 non-diabetic individuals, and found no difference between those with a high or low body mass index (BMI), or high or low insulin sensitivity. In contrast, circulating levels of other adipose tissue derived factors such as adiponectin, plasminogen activator inhibitor- 1 and leptin were markedly influenced by these parameters. Nor did resistin correlate with visceral fat accumulation, although visceral fat is a strong determinant of insulin sensitivity. 
Fig. 1 Putative role of adipokines in insulin sensitivity and glucose metabolism in man

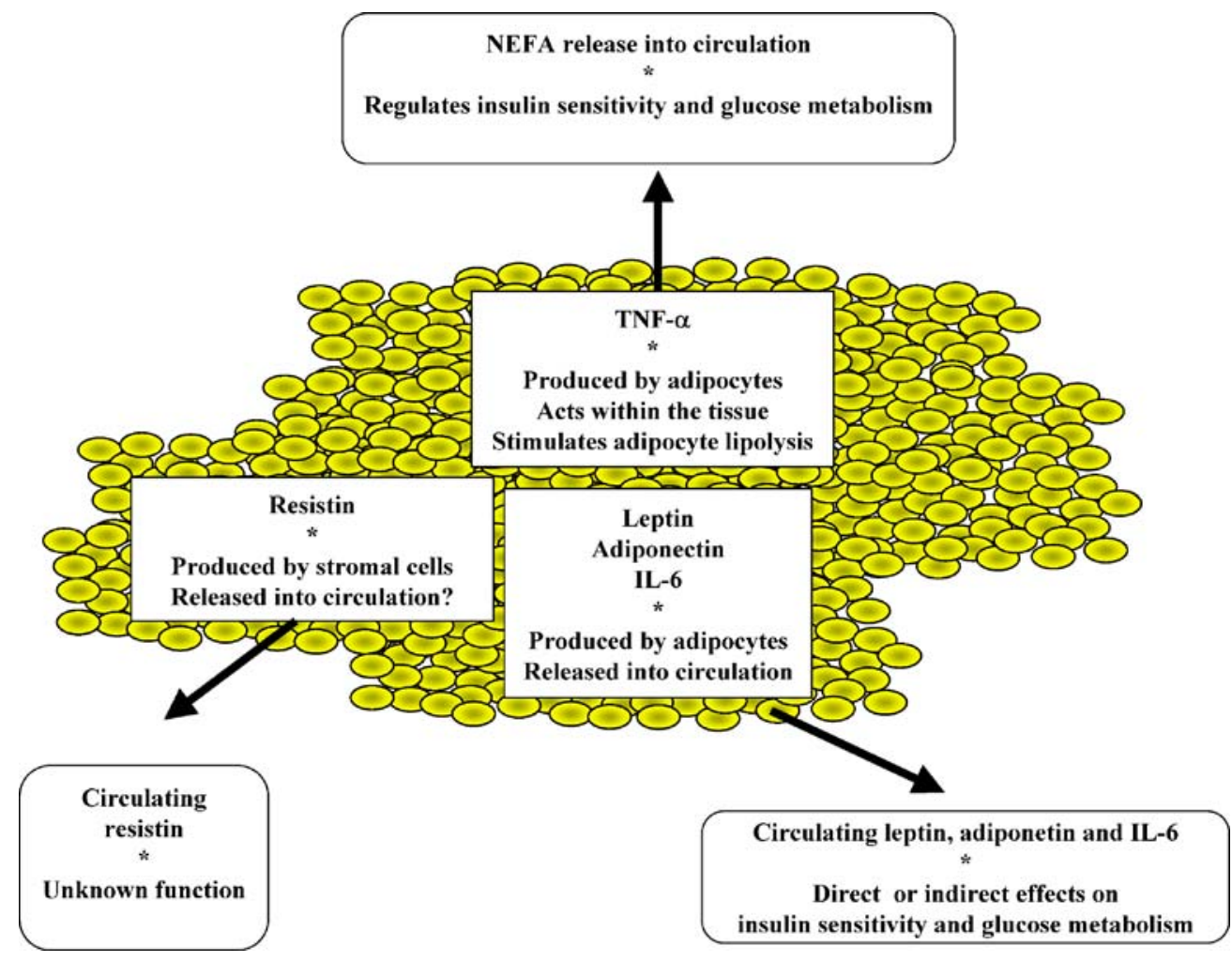

These results demonstrate rather convincingly that circulating resistin does not provide a link between adipose tissue and insulin sensitivity in man but, as the authors point out, this does not exclude other possible roles for resistin within human adipose tissue [12].

Do mice and men ever tell the same story about adipokines? In some cases they do. Leptin seems as pivotal in humans as in mice for regulation of body weight, in that leptin-deficient humans develop severe childhood-onset obesity, which can be cured by injections with recombinant leptin [13]. Many human studies have shown that circulating adiponectin [14] is correlated with insulin sensitivity, and that intravenous administration of adiponectin has similar effects on glucose metabolism and insulin sensitivity in men as in the mouse.

Links between adipokines, insulin sensitivity and glucose metabolism in man are summarised in Fig. 1. Adiponectin is a true adipokine as it is produced by fat cells, released into the circulation and directly regulates glucose metabolism and insulin sensitivity in liver and skeletal muscle. Leptin is another true adipokine, but has indirect effects on insulin sensitivity via regulation of appetite and energy expenditure in the brain. TNF- $\alpha$ is a true adipokine but only acts locally; an important local effect is stimulation of lipolysis and enhanced NEFA release into the circulation. NEFAs influence insulin sensitivity and glucose metabolism in the liver and skeletal muscle via well-defined mechanisms but, unlike most of the adipokines, they also influence insulin production by the pancreas. IL-6 is another true adipokine that influences insulin sensitivity in other organs, but its clinical role is less well established than that of adiponectin. Resistin, on the other hand, is not a true adipokine, and is produced by unidentified cells within the stroma of adipose tissue. Its function in man is unknown, yet is unlikely to involve insulin sensitivity. In fact, it still remains to be established whether circulating resistin is derived from adipose tissue or from another compartment in man.

It is therefore time to raise a warning flag when it comes to extrapolation of data from mouse models to adipokine action in man. In many instances (adipisin, resistin, IL-6) the mouse concept has provided a false trail. In one instance (TNF- $\alpha$ ) the mouse adipokine is reduced to a local factor. Editors of the prestigious journals in which the original reports on mouse adipokines have often been published should in future ask for supporting data in humans before allowing any further conclusions to be drawn.

\section{References}

1. Arner P (2005) Insulin resistance in type 2 diabetes - role of the adipokines. Curr Mol Med 5:333-339

2. Rosen BS, Cook KS, Yaglom J et al (1989) Adipsin and complement factor D activity: an immune-related defect in obesity. Science 244:1483-1487

3. Napolitano A, Lowell BB, Damm D (1994) Concentrations of adipsin in blood and rates of adipsin secretion by adipose tissue in humans with normal, elevated and diminished adipose tissue mass. Int J Obes Relat Metab Disord 18:213-218

4. Hotamisligil GS, Shargill NS, Spiegelman BM (1993) Adipose expression of tumor necrosis factor-alpha: direct role in obesitylinked insulin resistance. Science 259:87-91

5. Mohamed-Ali V, Goodrick S, Bulmer K, Holly JM, Yudkin JS, Coppack SW (1999) Production of soluble tumor necrosis factor receptors by human subcutaneous adipose tissue in vivo. Am J Physiol Endocrinol Metab 277:E971-E975 
6. Paquot N, Castillo MJ, Lefebvre PJ, Scheen AJ (2000) No increased insulin sensitivity after a single intravenous administration of a recombinant human tumor necrosis factor receptor: Fc fusion protein in obese insulin-resistant patients. J Clin Endocrinol Metab 85:1316-1319

7. Wallenius V, Wallenius K, Ahren B, Rudling M, Carlsten H, Dickson SL, Ohlsson C, Jansson JO (2002) Interleukin-6deficient mice develop mature-onset obesity. Nat Med 8:75-79

8. Steppan CM, Bailey ST, Bhat S et al (2001) The hormone resistin links obesity to diabetes. Nature 409:307-312

9. Adeghate E (2004) An update on the biology and physiology of resistin. Cell Mol Life Sci 61:2485-2496

10. Nagaev I, Smith U (2001) Insulin resistance and type 2 diabetes are not related to resistin expression in human fat cells or skeletal muscle. Biochem Biophys Res Commun 285:561-564
11. Fain JN, Cheema PS, Bahouth SW, Lloyd Hiler M (2003) Resistin release by human adipose tissue explants in primary culture. Biochem Biophys Res Commun 300:674-678

12. Utzschneider KM, Carr DB, Tong J et al (2005) Resistin is not associated with insulin sensitivity or the metabolic syndrome in humans. Diabetologia DOI 10.1007/s00125-005-1932-y

13. Farooqi IS, Jebb SA, Langmack G et al (1999) Effects of recombinant leptin therapy in a child with congenital leptin deficiency. N Engl J Med 341:879-884

14. Duntas LH, Popovic V, Panotopoulos G (2004) Adiponectin: novelties in metabolism and hormonal regulation. Nutr Neurosci 7:195-200 